\title{
Simultaneous Decision-Making in Competitive and Cooperative Environments ${ }^{*}$
}

\author{
Anya Savikhin ${ }^{\mathrm{a}}$ and Roman M. Sheremeta ${ }^{\mathrm{b}}$ \\ ${ }^{a}$ Becker Center on Chicago Price Theory, The University of Chicago Booth School of Business \\ 5807 South Woodlawn Avenue, Chicago, IL 60637, U.S.A. \\ ${ }^{\mathrm{b}}$ Argyros School of Business and Economics, Chapman University, \\ One University Drive, Orange, CA 92866, U.S.A.
}

April 21, 2010

\begin{abstract}
We experimentally investigate simultaneous decision-making in two contrasting environments: a competitive environment (a contest) and a cooperative environment (a voluntary contribution mechanism). We find that the cooperative nature of the voluntary contribution mechanism spills over to the contest, decreasing sub-optimal overbidding in the contest. However, contributions to the public good are not affected by simultaneous participation in the contest. There is a significant negative correlation between decisions made in competitive and cooperative environments, i.e. more cooperative subjects tend to be less competitive and vice versa. This correlation can be rationalized by heterogeneous social preferences towards inequality but not by bounded rationality theory.
\end{abstract}

JEL Classifications: C72, C91

Keywords: cooperation, competition, public goods, contests, experiments, behavioral spillover

Corresponding author: Anya Savikhin, anya@purdue.edu

* We thank Jack Barron, Tim Cason, David Dickinson, Justin Krieg, Casey Rowe, seminar participants at Purdue University, and participants at the 2009 Economic Science Association conference for helpful comments. Any remaining errors are ours. 


\section{Introduction}

Individuals, firms, and policy makers simultaneously interact in many different environments in practice. At the store checkout line an individual may choose how much to spend on lottery tickets (thus participating in a contest) and how much to donate to a charity (thus providing a public good). In the workplace, workers compete with each other for promotions while simultaneously working together on various tasks that are assigned to them. Farm owners may compete daily with each other in the market for their products and at the same time they may cooperate to build facilities that would be mutually beneficial to reduce waste management costs.

The novel contribution of the current study is that we experimentally investigate individual behavior when competitive and cooperative environments are present simultaneously. To induce two contrasting environments, we employ a voluntary contribution mechanism (cooperative environment) and a lottery contest (competitive environment). In the voluntary contribution mechanism (VCM), individuals make contributions in order to provide a public good. In the contest, individuals make bids in order to win a prize. The fundamental difference between these two games is that bids in the contest exert a negative externality on others, while contributions in the VCM exert a positive externality. The findings from the literature when these games are played in isolation are clear and robust. In contests, individuals over-bid relative to socially optimal levels (Davis and Reilly, 1998; Potters et al., 1998; Sheremeta, 2010a,c). ${ }^{1}$ In VCMs, individuals contribute half-way between the equilibrium free riding and the Pareto

\footnotetext{
${ }^{1}$ It is also documented that over-bidding decreases with experience (Davis and Reilly, 1998), groups make lower bids than individuals (Sheremeta and Zhang, 2010), and constraining individual endowments reduces over-bidding (Sheremeta, 2010a).
} 
optimal level, with contributions declining over time (Ledyard, 1995; Fischbacher et al., 2001). ${ }^{2}$ The contest is similar in practice to a wide variety of situations such as patent races, political contests, competitions for promotions in the workplace, or advertising campaigns. The VCM is similar to another broad class of situations, including the decision to volunteer for various groups or associations and voluntary monetary contributions to public goods or charities. The design of the experiment also permits us to analyze the correlation between each individual's bid in the contest and his or her contribution in the VCM.

The standard assumption in game theory is game independence, suggesting that the institutional context in which a decision is made does not matter. This assumption is questioned by recent experiments, which find that context matters greatly in some environments. Behavioral spillovers occur when games are played simultaneously, causing behaviors exhibited in one game to be carried over to the other game in a predictable way (Huck et al., 2007; Bednar et al., 2009; Falk et al., 2009; Cason et al., 2009). Bednar et al. (2009) report a laboratory experiment with different two-player games and find that simultaneous game-play differs from isolated controls. Cason et al. (2009) report a laboratory experiment where the same group of five players participate in two different coordination games and find that cooperative behavior spills over from one game to the other. ${ }^{3}$ Huck et al. (2007) study two dissimilar two-player games played simultaneously and find that learning spillovers occur when feedback is not readily available for each game. On the contrary, Falk et al. (2009) investigate groups of different individuals playing two identical coordination games or two identical public goods games, and find that behavior

\footnotetext{
${ }^{2}$ Contributions increase when subjects are allowed to punish, assign disapproval points, send signals, or communicate with other subjects prior to contributions in the VCM (Ledyard, 1995; Fehr and Gachter, 2000).

${ }^{3}$ Cherry et al. (2003) and Cherry and Shogren (2007) also find that rationality exhibited in one setting affects behavior in a disparate setting introduced sequentially. Dickinson and Oxoby (2009) find that optimistic or pessimistic expectations developed in one setting can carry over to acceptance rates in an ultimatum game.
} 
does not differ from the baseline where only one game at a time is played. ${ }^{4}$ The main difference of our study is that we investigate behavior in both competitive and cooperative environments, while previous studies consider coordination and public good games (Falk et al., 2009; Cason et al., 2009) or bi-matrix games such as the prisoner’s dilemma (Bednar et al., 2009).

We find that overbidding in the contest is significantly reduced when individuals simultaneously participate in the VCM. This is a favorable outcome because overbidding in contests leads to sub-optimal results. However, we do not find significant differences in VCM contributions between the simultaneous-play and baseline treatments. We also find that there is a negative correlation between decisions made in the lottery contest and in the VCM, suggesting that individuals who are more competitive tend to be less cooperative and vice versa. As discussed in the conclusion, this research has broad implications for political and management institutional design, and for related research that attempts to solve problems of overbidding in contests and under-contribution in public goods.

\section{Experimental Design}

\subsection{Theoretical Predictions}

The experimental design employs two games, a lottery contest and a VCM. The lottery contest is based on the theoretical model of Tullock (1980). In this contest, $N$ identical riskneutral players with initial endowment levels $e$ compete for a prize $V$ by submitting bids. The probability that a player $i$ wins the prize is equal to player $i$ 's own bid $b_{i}$ divided by the sum of all players' bids. Given this, the expected payoff from the contest for player $i$ can be written as:

\footnotetext{
${ }^{4}$ Other existing studies consider simultaneous interaction in several public goods environments, either breaking a single public good into multiple parts or presenting multiple public goods (Bernasconi et al., 2009; Biele et al., 2008; Fellner and Lunser, 2008).
} 


$$
\pi_{i}^{C}=e-b_{i}+V b_{i} / \sum_{j} b_{j} .
$$

Differentiating (1) with respect to $b_{i}$ and accounting for the symmetric Nash equilibrium leads to the classic solution of $b^{*}=V(N-1) / N^{2}$, while the socially optimal level of bids is $b^{S O}=0$.

The VCM is based on a linear public goods game where $N$ identical risk-neutral players choose a portion of their endowments $e$ to contribute to a public good (Groves and Ledyard, 1977). Player $i$ 's contribution $c_{i}$ to the public good is multiplied by $m \in(0,1)$ and given to each

of $N$ players in the group, where $m \times N>1$. Thus, the payoff from the VCM for player $i$ can be written as:

$$
\pi_{i}^{V C M}=e-c_{i}+m \sum_{j} c_{j} .
$$

The Nash equilibrium in the VCM is to free ride by contributing nothing, $c^{*}=0$, while the socially optimal solution is to contribute one's full endowment to the public good, $c^{S O}=e$.

In the VCM (2), over-contribution relative to the Nash equilibrium leads to outcomes that are closer to the socially optimal result. On the other hand, in the contest (1), overbidding is socially wasteful and the most socially desirable outcome is for everybody to bid nothing. Note that playing the games in ensemble does not change the standard Nash equilibrium prediction in either game.

\subsection{Experimental Procedures}

The experiment was conducted at the Vernon Smith Experimental Economics Laboratory. Volunteers were recruited from a pool of undergraduate students from Purdue University. A total of 120 subjects participated in 6 sessions, with 20 subjects participating in each session. All subjects participated in only one session of this study. Some students had participated in other economics experiments that were unrelated to this research. 
The computerized experimental sessions used z-Tree (Fischbacher, 2007) to record subject decisions and also (in the Contest-VCM treatment) to record the order of decisions. We conducted three treatments as summarized in Table 1: a baseline Contest treatment, a baseline VCM treatment, and a treatment in which these two games were played simultaneously. ${ }^{\mathbf{5}}$ Subjects were given the instructions, shown in the appendix, at the beginning of the session and the experimenter read the instructions aloud. In each session, 20 subjects were randomly assigned to groups of $N=4$ players and stayed in the same group throughout the entire experiment, playing each game for a total of 20 periods.

Table 1: Summary of Treatments

\begin{tabular}{lcccc}
\hline \hline Treatment & Game Played & $\begin{array}{c}\text { Number of } \\
\text { Sessions }\end{array}$ & $\begin{array}{c}\text { Number of } \\
\text { Subjects }\end{array}$ & $\begin{array}{c}\text { Number of Independent } \\
\text { Observations }\end{array}$ \\
\hline Baseline Contest & Contest & 2 & 40 & 10 \\
Baseline VCM & VCM & 2 & 40 & 10 \\
Contest-VCM & Contest \& VCM & 2 & 40 & 10 \\
\hline
\end{tabular}

At the beginning of each period, subjects received endowments of 80 francs in the contest (or VCM) and were asked to enter their bids (or contributions in the VCM). In the lottery contest, subjects competed with each other for the prize value of $V=80$ francs. In the VCM, each subject chose a portion of the 80 franc endowment to contribute to the public good, and kept the other portion for himself. Each player's contribution to the public good was multiplied by $m=0.4$ and the total of all contributions given to each of the 4 players in the group. Subjects did not know others' decisions before making their own decisions. After all subjects made their decisions, the sum of all bids (or contributions in the VCM) in each group was displayed on the

\footnotetext{
${ }^{5}$ Note that treatments with two simultaneous contests or two simultaneous public goods are also possible as baselines. We believe that our Baseline Contest and Baseline VCM treatments are more appropriate for several reasons. First, this design allows us to see if behavior in ensemble games is different from behavior in isolated games. Second, there is no reason to believe that behavior in either the contest or the VCM would change if two of the same games were played in ensemble, as documented by Falk et al.'s (2009) for the case of two VCMs.
} 
output screen together with the outcome, and earnings were determined. Subjects recorded their results in a record sheet, and then moved on to the next period.

During the Contest-VCM treatment, the contest and VCM games were displayed side by side on the same screen. ${ }^{6}$ Subjects received a separate endowment in the contest and a separate endowment in the VCM at the beginning of each period. These endowments could not be transferred between games. Subjects typed their choices into each input box, and clicked "submit" at the bottom of the screen before moving on to the next period. To account for any order effect within each period, in one of the two Contest-VCM sessions, the contest game was displayed on the left (the VCM game was on the right), and in the other Contest-VCM session, the contest game was displayed on the right (the VCM game was on the left). During the decision-making stage in the Contest-VCM sessions, subjects were instructed to click on the input box for that game, and then enter their decision. A function was executed in $\mathrm{z}$-Tree that kept track of which input box the subject clicked on first. ${ }^{7}$

At the end of the experiment, two periods from the game were selected for payment using a random draw from a bingo cage. In the Contest-VCM treatment, two periods from each game (contest and VCM) were selected using the same method. Experimental francs were used throughout the experiment, with a conversion rate of 25 francs $=\$ 1$. Subjects earned $\$ 18$ on average, and sessions (including instruction time) lasted approximately 75 minutes. Subjects also completed a demographic questionnaire at the end of each session.

\footnotetext{
${ }^{6}$ We used categorical (and not ordinal) nomenclature to label each game, the colors blue and green (instead of, for example, 1 and 2 or $\mathrm{A}$ and $\mathrm{B}$ ).

${ }^{7}$ When the contest game was displayed on the left, subjects made a decision in the contest game first $92 \%$ of the time. When the VCM was displayed on the left, subjects made a decision in the VCM game first 93\% of the time. This is unsurprising, given that over $95 \%$ of subjects in the experiment self-reported that they read and write from left to right horizontally in their native language, and that all instructions were in English, which reads from left to right. We do not find any difference between individual behavior in the two Contest-VCM sessions; therefore, we pool the sessions.
} 


\section{Results \& Discussion}

\subsection{Overview}

Table 2 reports the average contribution in the VCM and the average bid in the contest across all treatments. According to the theory, the unique equilibrium bid in the contest is $b^{*}=$ 15. In contrast to the theoretical prediction, we find significant over-bidding of about $120 \%$ in the baseline contest treatment. This finding is consistent with previous experimental findings, which document that subjects overbid by up to $200 \%$ relative to the theoretical predictions (Davis and Reilly, 1998; Potters et al., 1998; Sheremeta, 2010b,c). As the result of over-bidding, subjects earn significantly lower payoffs than is predicted by the theory. ${ }^{8}$

Table 2: Average Statistics

\begin{tabular}{lcccc}
\hline \hline Treatment & Equilibrium & $\begin{array}{c}\text { Contest- } \\
\text { VCM }\end{array}$ & $\begin{array}{c}\text { Baseline } \\
\text { VCM }\end{array}$ & $\begin{array}{c}\text { Baseline } \\
\text { Contest }\end{array}$ \\
\hline Value of the Prize in Contest, $V$ & 80 & 80 & & 80 \\
MPCR in VCM, $a$ & 0.4 & 0.4 & 0.4 & \\
Number of Players, $N$ & 4 & 4 & 4 & 4 \\
\hline Bid in Contest & 15 & $26.8(0.8)$ & & $33.5(0.8)$ \\
Payoff in Contest & 105 & $73.2(1.2)$ & & $66.5(1.2)$ \\
Contribution in VCM & 0 & $22.4(0.9)$ & $23.9(1.0)$ & \\
Payoff in VCM & 80 & $93.4(0.7)$ & $94.3(0.8)$ & \\
\hline
\end{tabular}

Standard error of the mean in parentheses.

The unique equilibrium prediction for contributions in the VCM is $c^{*}=0$. However, any over-contribution relative to the equilibrium leads to more desirable outcomes; specifically, contribution of the full endowment results in the most socially optimal outcome. Relative to theoretical predictions, we find significant over-contribution in the VCM in all treatments. This finding is consistent with previous experimental studies, which report that over-contribution is common in public goods environments due to altruism or social norms (Ledyard, 1995). Fehr

\footnotetext{
${ }^{8}$ To determine the net payoff from the contest, subtract the endowment of 80 from payoffs in Table 3.1 .
} 
and Gachter (2000) report contribution levels at $40-60 \%$ of the endowment during the experiment, with contributions falling to $27 \%$ in the final period. Note that as the result of overcontribution, subjects' payoffs in the VCM are significantly higher than the equilibrium prediction.

Result 1. Relative to theoretical predictions, there is significant over-bidding in the contest and significant over-contribution in the VCM in all treatments.

\section{Figure 1: Distribution of Bid/Contribution}

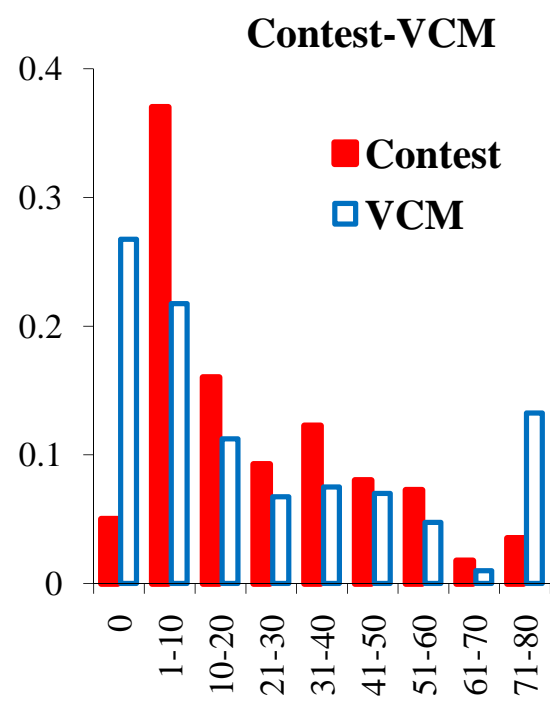

Contribution (Bid)

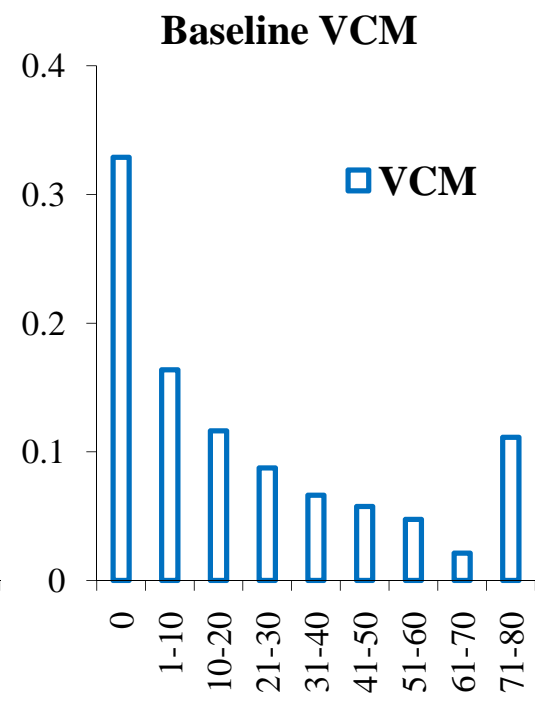

Contribution

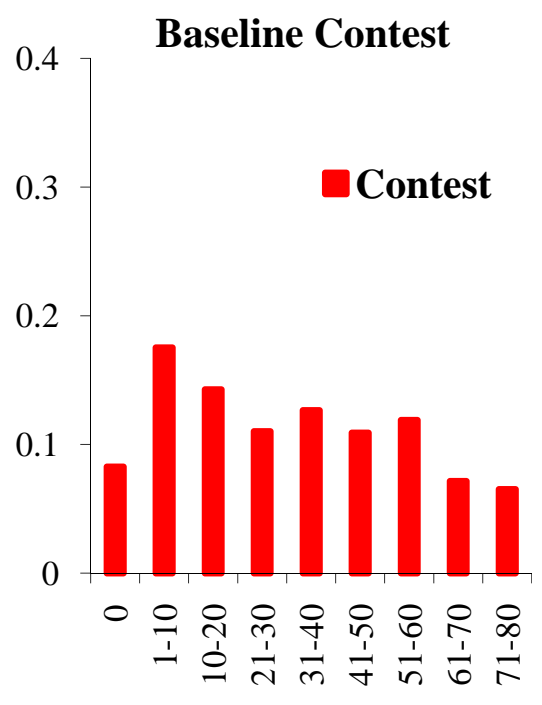

Bid

Figure 1 displays the distribution of contributions in the VCM and bids in the contest over all periods by treatment. Individual bids in the contest are distributed on the entire strategy space, contrary to the unique pure strategy Nash equilibrium of 15. Individual contributions in the VCM are also distributed on the entire strategy space, contrary to the unique pure strategy Nash equilibrium of 0 . A high variance in individual bids is consistent with previous experimental findings in the contest (Davis and Reilly, 1998; Potters et al., 1998; Sheremeta, 2010a,b). The distribution of contributions in the VCM is also consistent with previous experimental findings (Ledyard, 1995; Fehr and Gachter, 2000; Fischbacher et al., 2001). 


\subsection{Comparison of Simultaneous with Baselines}

Figure 2 displays the average contribution and the average bid over all 20 periods of the experiment for the baseline and Contest-VCM treatments. In order to study the effect of displaying two games simultaneously, we examine decisions in the first five periods and decisions in the last five periods. ${ }^{9}$ In the baseline VCM treatment, the average contribution in the VCM starts at 36.7 in the first five periods and decreases to 12.6 in the last five periods. Similarly, in the Contest-VCM treatment, the average contribution starts at 35.6 in the first five periods and decreases to 11.5 in the last five periods. A regression of the contribution on a period trend shows a significant and negative relationship for both treatments ( $p$-value $<0.01)$. The difference between contributions in the baseline VCM and Contest-VCM treatments is not statistically significant based on a Wilcoxon rank-sum test $(p$-value $=0.54) .{ }^{10}$

Result 2: Simultaneously participating in the contest does not have a significant effect on contributions in the VCM.

Related literature reports that when playing two simultaneous public goods games with different groups, individuals are influenced in each game by the contributions of their own group members, and not by the contributions of the other group members (Falk et al., 2009). We find that even when playing with the same subjects, bids in the contest do not influence contributions to the public good. This is consistent with Falk et al.'s (2009) observation that the abstraction to

\footnotetext{
${ }^{9}$ Note that while comparison of decisions made in period 1 may be more appropriate for understanding decision making without the influence of the concurrently displayed game, we average decisions across the first five periods because subjects are still learning in the first few periods. We compare decision-making at the beginning of the session (first five periods) to decision-making at the end of the session (last five periods).

${ }_{10}$ The non-parametric tests use the average contribution (bid) in each group across all the periods for each observation, and groups in this fixed matching design are statistically independent.
} 
study public goods behavior in laboratory games, where individuals are only participating in one game, may be a good approximation for behavior in practice. ${ }^{11}$

Figure 2: Average Bid/Contribution by Treatments

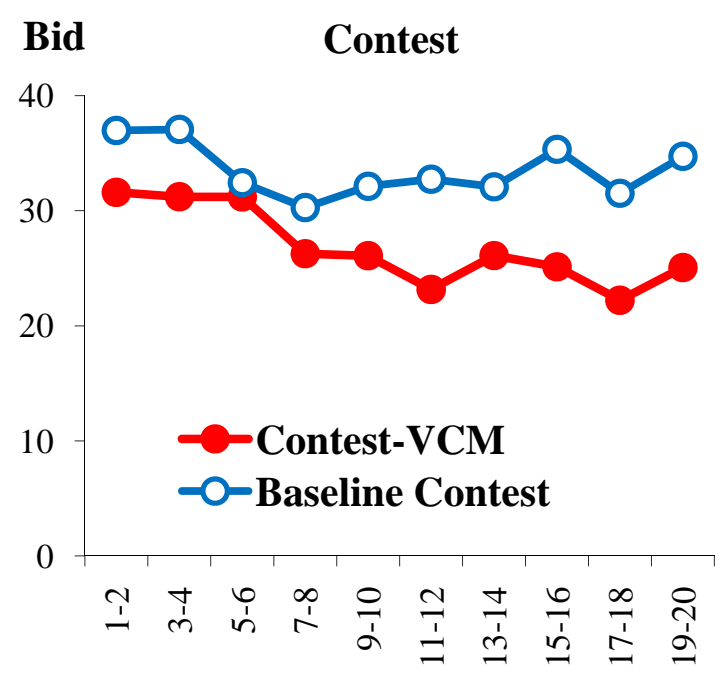

Period

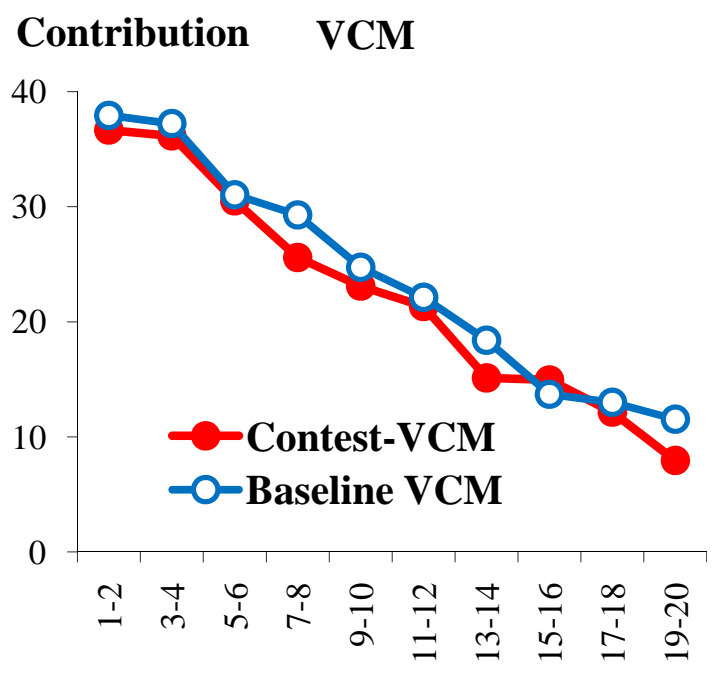

Period

In the baseline Contest treatment, the average bid starts at 36.5 in the first five periods and decreases to 33.7 in the last five periods. In the Contest-VCM treatment, the average bid in the contest starts at 31.5 in the first five periods and decreases to 24.4 in the last five periods. A regression of the bid on a period trend shows a significant and negative relationship for the Contest-VCM treatment $(p$-value $<0.01)$ but not for the baseline Contest treatment $(p$-value $=$ 0.21). ${ }^{12}$ Overall, the declining bid trend is consistent with previous research, documenting that over-bidding decreases over time (Davis and Reilly, 1998; Sheremeta, 2010a,c).

\footnotetext{
${ }^{11}$ Note that in the Falk et al. (2009) and in our study, endowments are not shared between the two games; rather, subjects receive a set endowment for each game. This result may be most applicable in this setting, but whether this result holds when endowments are shared across simultaneous games could be considered in future work.

${ }^{12}$ However, when controlling for the lagged bids, we find a significant period trend in both treatments (see Table 3.2).
} 
The difference between bids in the baseline Contest and Contest-VCM treatments is statistically significant based on a Wilcoxon rank-sum test ( $p$-value $=0.06,2$-tailed test). ${ }^{13}$ Figure 3 displays, by group, the average over-dissipation rates, defined as the ratio of the total sum of bids to the value of the prize. On average, groups in the baseline Contest treatment have greater over-dissipation rates than groups in the Contest-VCM treatment. This difference in behavior can be explained by the developing literature on simultaneous decision-making, which suggests that behavior spills over from one game to another in predictable ways (Cason et al., 2009; Bednar et al., 2009). ${ }^{14}$ We provide a more detailed discussion in Section 4.3.

Result 4: Simultaneously participating in the VCM significantly reduces overbidding in the contest.

\section{Figure 3: Over-dissipation Rates by Groups}
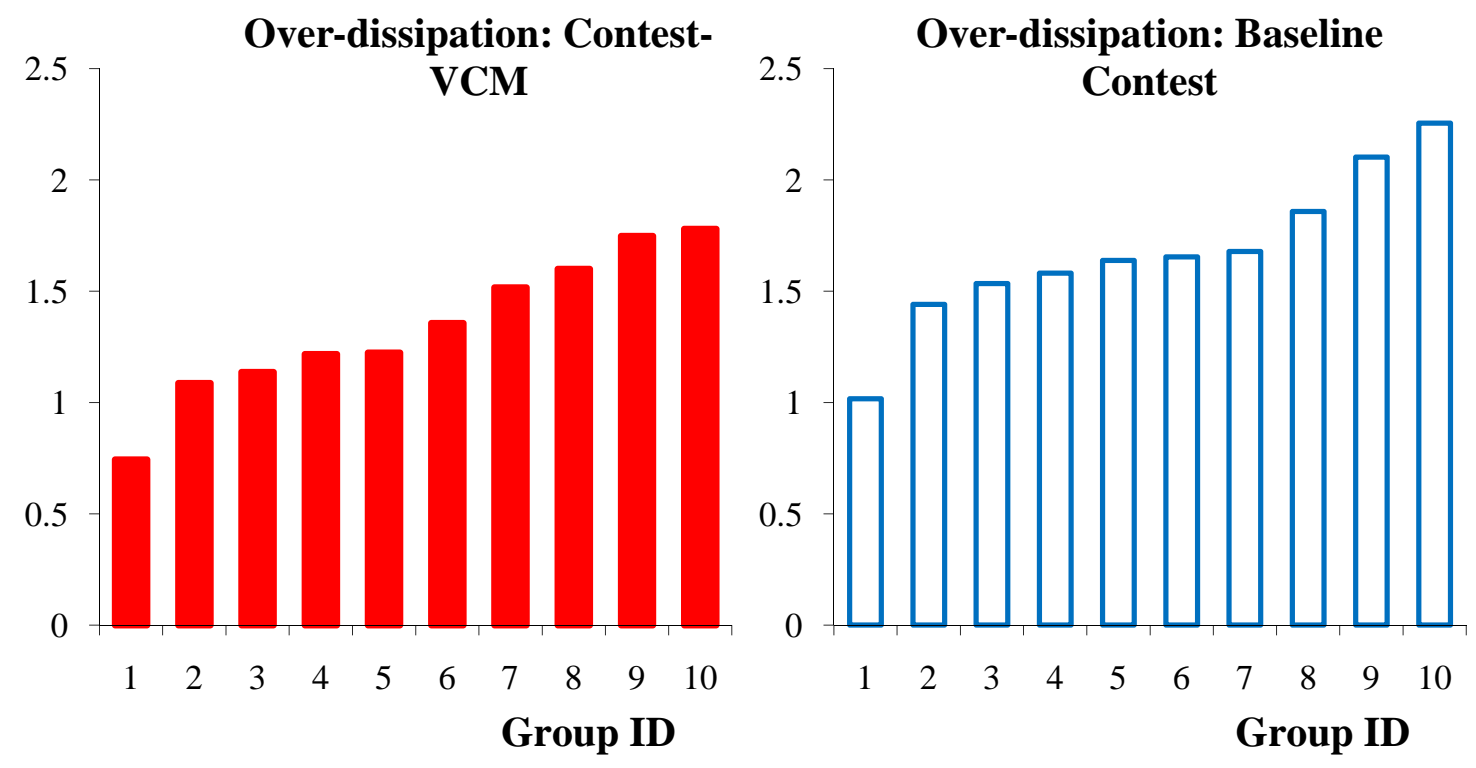

\footnotetext{
${ }^{13}$ This difference is especially significant when looking at the last 10 periods of the experiment ( $p$-value $<0.01$ ).

${ }^{14}$ Cason et al. (2009), for example, find that participating in a more cooperative environment can work to increase cooperation in a less cooperative environment. Likewise, we find that participating in the cooperative VCM environment helps to reduce competitive over-bidding in the contest.
} 
Table 3: Regression Models of Individual Subject Choices

\begin{tabular}{|c|c|c|c|c|}
\hline Dependent Variable: & Con & Bid & VCM C & ibution \\
\hline & (1) & (2) & (3) & (4) \\
\hline Individual Subject Choices in & $\begin{array}{l}\text { Baseline } \\
\text { Contest }\end{array}$ & $\begin{array}{l}\text { Contest- } \\
\text { VCM }\end{array}$ & $\begin{array}{c}\text { Baseline } \\
\text { VCM }\end{array}$ & $\begin{array}{l}\text { Contest- } \\
\text { VCM }\end{array}$ \\
\hline Contest Bid & & & & $\begin{array}{l}-0.31 \\
(0.19)\end{array}$ \\
\hline VCM Contribution & & $\begin{array}{l}-0.13^{*} \\
(0.06)\end{array}$ & & \\
\hline Lag of Group Contest Bid & $\begin{array}{c}0.02 \\
(0.02)\end{array}$ & $\begin{array}{l}0.08^{* *} \\
(0.02)\end{array}$ & & \\
\hline Lag of Group VCM Contribution & & & $\begin{array}{c}0.14^{* *} \\
(0.01)\end{array}$ & $\begin{array}{c}0.19^{* *} \\
(0.01)\end{array}$ \\
\hline Inverse of Period & $\begin{array}{c}17.35 * * \\
(5.87)\end{array}$ & $\begin{array}{c}29.8^{* *} \\
(2.5)\end{array}$ & $\begin{array}{c}39.52^{* *} \\
(7.12)\end{array}$ & $\begin{array}{c}30.8^{* * *} \\
(10.00)\end{array}$ \\
\hline Observations & 760 & 760 & 760 & 760 \\
\hline Number of subjects & 40 & 40 & 40 & 40 \\
\hline
\end{tabular}

We find that bid choices in the contest are influenced by contribution choices in the VCM, but that contribution choices in the VCM are not affected by bid choices in the contest. Table 3 reports regression results that also support these findings. We estimate regressions separately for the contest and the VCM, using the subjects' choices as the dependent variable. A period trend, the bid (contribution), and lagged total group bid (contribution) are the independent variables. The previous period group choices in each game positively influence the current choice in all treatments (however, this effect is not significant in specification 1). This suggests that, in line with previous VCM and contest studies, subjects' decisions in the current period are influenced by their group members' decisions in the previous period (Croson et al., 2005; Sheremeta, 2010a). In the Contest-VCM treatment, we also find that the individual's contribution in the current period negatively affects the individual bid in the current period (column 2), while the individual's bid in the current period does not affect the individual's 
contribution in the current period (column 4). The estimation of equations in columns (2) and (4) used a simultaneous equation system since subjects made both game decisions at the same time. ${ }^{15}$ These findings support Results 3 and 4 - that simultaneous participation in the contest does not have a significant effect on VCM contributions, but that simultaneous participation in the VCM has a significant effect on contest bids.

\subsection{Behavioral Effects}

As in previous work (Bednar et al., 2009; Cason et al., 2009), we use the concepts of cognitive load and behavioral spillover to explain the change in behavior when games are played simultaneously. Both effects can be applied as possible explanations for Results 3 and 4 . The cognitive load effect suggests that due to limited cognitive abilities, the subject's behavior in a more complex game may be affected by decision-making strategies from the easier game. The behavioral spillover effect suggests that behavior can "spill over" from one game to another when the two games are played simultaneously.

Cognitive load is a construct in psychology representing the burden that performing a task imposes on the learner's cognitive system (Simon, 1982; Paas and van Merrienboer, 1994). Playing ensembles of games increases cognitive load, which causes subjects to apply common analogies to disparate bargaining situations, and this has been modeled formally by Samuelson (2001). When a problem is complex and requires high cognitive load, individuals may use heuristics or "rules of thumb" to make decisions (Wright, 1980; Gigerenzer et al., 1996). In the present context, cognitive limitations may cause subjects to apply similar strategies to the contest

\footnotetext{
${ }^{15}$ We used session dummy-variables to control for session effects. The estimation results are very similar when using individual subject dummy-variables to control for individual subject effects. The only exception is that in specification (2) the VCM Contribution variable is no longer significant. The main reason is that in the estimation of simultaneous equation system with subject dummy-variables we need to use too many degrees of freedom.
} 
and VCM in order to reduce cognitive burdens. Specifically, strategies from lower cognitive load games could be applied to games with higher cognitive load. Psychologists propose various methods for measuring cognitive load; for an overview, see Paas et al. (2003). A relevant measure for assessment of cognitive load is the complexity of the game. We posit that cognitive load is greater in the contest than in the VCM. First, the contest involves greater uncertainty than the VCM. In the VCM, each subject forms beliefs about other's contributions and determines her probable outcome. In the contest, on the other hand, each subject must first form beliefs about other's bids and then form a belief about the probability that her bid will win, where this probability also depends on other group members' bids. ${ }^{16}$ Second, the decision-making process in the contest is much more involved than in the VCM, and while the equilibrium of the VCM is in dominant strategies, the equilibrium for the contest is not. Moreover, the payoff function is flatter (and concave) in the contest than in the VCM. For the above reasons, the cognitive load effect should cause the subject to use strategies from the VCM to motivate her behavior in the contest, thus lowering contest bids.

The direction of behavioral spillover can be predicted by the level of strategic uncertainty and social interaction effects in the two games. Cason et al. (2009) posit that games with lower strategic uncertainty have a stronger behavioral spillover effect onto other games, and use a measurement of volatility to describe the degree of strategic uncertainty. Similarly, we propose that the behavioral spillover effect causes behavior in games with a lower volatility of individual decisions across different periods to "spill over" onto games with a higher volatility of decisions. We measure the degree of volatility in individual decision-making by computing the absolute difference between the decisions made in period $t$ and period $t-1$. We find that in the Contest-VCM treatment, the average volatility of bids in the contest is higher than the average

\footnotetext{
${ }^{16}$ Understanding probability can be difficult for subjects due to bounded rationality (Camerer, 2003).
} 
volatility of contributions in the VCM (14.8 versus 12.2) ${ }^{17}$ This result suggests that the VCM game should have a stronger behavioral spillover effect onto the contest.

Falk et al. (2009) find that behavior in public goods games is in large part influenced by the social interaction effect, which suggests that individuals change their behavior in response to changes in their respective group members' behavior. Another possible explanation for the direction of the behavioral spillover is that there is a greater social interaction effect in the VCM as compared to the contest, which implies that behavior in the contest should not influence behavior in the VCM, while behavior in the VCM should influence behavior in the contest. To measure the social interaction effect, we separately estimated regressions for each individual in the baseline treatments. The dependent variable is the total of other group's contributions (bids) in the previous period and the independent variable is the subject's contribution (bid) in the current period. The coefficient on lagged group choices is statistically significant for 4 out of 40 subjects in the contest and 10 out of 40 subjects in the public good. Moreover, in all of the regressions which were statistically significant in the VCM, the effect moves in a predictable direction - all coefficients on previous group choices are negative, even after accounting for the linear period trend. On the other hand, there is no such pattern in the contest. Another way to measure the social interaction effect is to compare the volatility of choices across individuals within each group over time. In the contest, the average standard deviation of bids across all groups is 15.1 in periods $1-5$ and 14.3 in periods $15-20$. In the VCM, the average standard deviation of contributions is 14.5 in periods $1-5$ and it falls to 8.1 in periods $15-20$. The substantial decrease in volatility of individual contributions in the VCM implies that the VCM

\footnotetext{
${ }^{17}$ When using the data from the baseline treatments, the average volatility in contests is 14.8 and in VCMs it is 13.4. Using the average volatility in bids and contributions within each group across all the periods as one independent observation, the sign test of matched pairs can reject the equality of volatilities at 0.1 significance level.
} 
has a stronger social interaction effect. ${ }^{18}$ The stronger social interaction effect in the VCM suggests that behavior in the VCM is less likely to have a significant spillover effect onto behavior in the contest. ${ }^{19}$

Finally, behavioral spillover can occur due to the presence of 'conditional cooperators' in the VCM game, i.e. subjects who contribute more to a public good the more others contribute (Fischbacher et al., 2001). The presence of conditional cooperators has been documented in the lab and in the field (Fischbacher et al., 2001; Keser and Winden, 2002; Harrison and List, 2004; Fischbacher and Gächter, 2006; Kocher et al., 2007; Herrmann and Thoni, 2009). The behavior of conditional cooperators is based on their perception of the "type" of individuals with whom they are interacting: for example, knowing that others are the "free-rider" type, conditional cooperators also free ride. In fact, any factor that influences beliefs about the nature of others' cooperation may influence the behavior of conditional cooperators (Gächter, 2006). If several games are present concurrently, the "type" of individual one is grouped with may be inferred from group members' behavior in any of the games present. In our experiment, conditional cooperators can form beliefs about types in their group in one game (contest or VCM), and apply these beliefs to a disparate game (VCM or contest). By reducing contest bids, subjects may signal their cooperative type to conditional cooperators in order to induce higher contribution to the VCM.

To summarize, we find that participation in the public goods environment influences individuals to bid less in the contest, which may occur due to several possible effects. Cognitive

\footnotetext{
${ }^{18}$ Note that the biggest difference between bids in the baseline Contest and Contest-VCM treatment is in the last five periods of the experiment (Figure 3.2). Volatility in VCM is the lowest in the last five periods as well.

${ }^{19}$ One could also argue that the VCM evokes a social norm of cooperation that reduces competitiveness in the contest (Brandenburger and Nalebuff, 1996). However, such argument would imply that, as contributions to the VCM decline (thus reducing social norms), bids in contests should increase. Figure 3.2 shows that this is clearly not the case, since both the contributions and bids decline over time in the Contest-VCM treatment.
} 
load may cause subjects to apply the strategy from the public goods game to the contest, decreasing bids. Discovering the direction of behavioral spillover is more complex. The strategic uncertainty effect may act to cause behavior in the VCM to spill over onto behavior in the contest. In addition, the presence of conditional cooperators may act to cause behavior in the VCM to spill over onto behavior in the contest.

\subsection{Correlation of Bids and Contributions}

Another contribution of our study is that we can directly compare bids in the contest with contributions in the VCM. This is possible because of the within-subjects design of the ContestVCM treatment. Figure 4 displays individual contributions and bids for the Contest-VCM treatment, averaged over periods 1-5 and periods 16-20. A Spearman's rank correlation test shows that individuals who contribute more to the VCM also bid less in contests in the first five periods of the game (correlation $-0.27, p$-value $<0.10$ ). ${ }^{20}$

Result 5. Subjects who bid more in the contest also tend to contribute less in the VCM.

To explain the negative correlation between bids and contributions, we consider two competing theories that are often employed to explain individual behavior in the public goods and contest experiments. The two common explanations for non-zero contributions to public goods are based on social preferences (Fehr and Schmidt, 1999; Sobel, 2005) and bounded rationality or mistakes (Andreoni, 1995; Anderson et al., 1998; Houser and Kurzban, 2002). The same arguments are also applied to explain over-bidding in contests (Herrmann and Orzen, 2008; Sheremeta, 2010a). The design of our novel Contest-VCM treatment enables us to distinguish

\footnotetext{
${ }^{20}$ We also used only the period 1 contributions and bids to look at correlation and found only slight insignificant correlation. It is likely that subjects are still learning in the first period and thus their decisions are noisy.
} 
between these two competing theories, as they generate opposing predictions for the correlation of bids and contributions.

Figure 4: Correlation of Bids and Contributions (Periods 1-5 and 16-20 averaged)
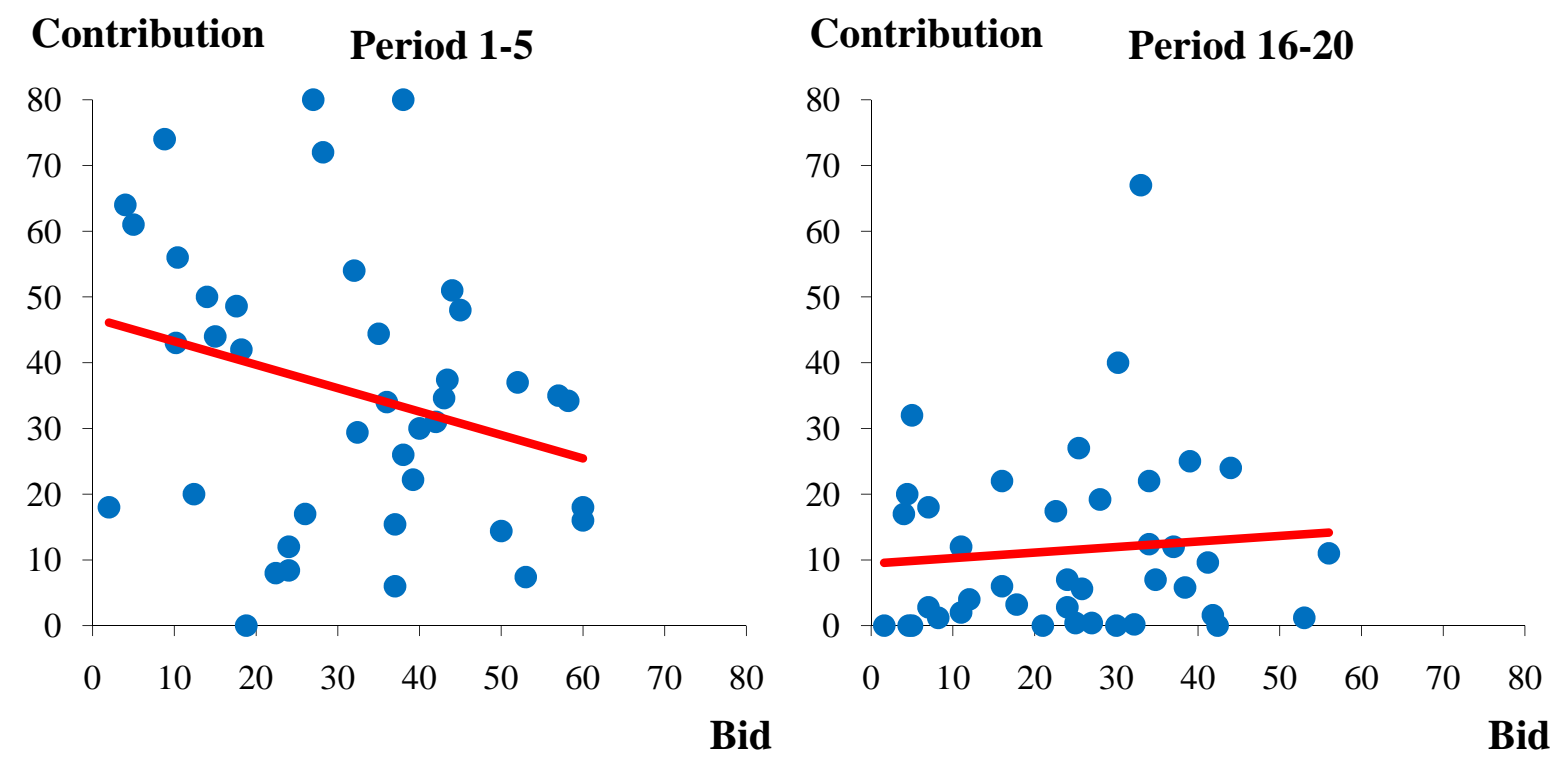

Social preferences are often cited as the reason why behavior is not in line with theory in many settings. A variety of social preference models may account for the negative correlation of bids and contributions, and our goal is not to distinguish among them. Rather, our objective is to present a simple model that can inform our findings, and we use the inequality aversion model because it is one which has been formally presented in both the VCM and contest literature as a possible justification for observed behavior (Fehr and Schmidt, 1999; Hermann and Orzen, 2008). In the public goods literature, Fehr and Schmidt (1999) show how inequality aversion may explain individual behavior in the VCM. In the contest literature, Grund and Sliwka (2005) and Herrmann and Orzen (2008) demonstrate that inequality aversion may account for overbidding. It is straightforward to show that inequality aversion can explain the negative 
correlation between bids and contributions. ${ }^{21}$ As in Fehr and Schmidt (1999), assume that subject $i$ suffers from inequality and his utility is given by:

$$
U_{i}\left(\pi_{i}, \pi_{-i}\right)=\pi_{i}-\alpha_{i} \frac{1}{N-1} \max _{i \neq j}\left\{\pi_{j}-\pi_{i}, 0\right\}-\beta_{i} \frac{1}{N-1} \max _{i \neq j}\left\{\pi_{i}-\pi_{j}, 0\right\} .
$$

This utility function assumes that subject $i$ dislikes disadvantageous inequality, i.e. if subject $i$ earns one less franc than subject $j$, his utility is reduced by $\alpha_{i}>0$ francs. Further, subject $i$ also dislikes advantageous inequality to some extent, $\beta_{i} \geq 0$, but not as much as disadvantageous inequality, i.e. $\alpha_{i}>\beta_{i}$. The utility function (3) implies that subjects who have higher disadvantageous inequality $\alpha$ should make lower contributions in the VCM in order to avoid the circumstance where they are the highest contributors with the lowest payoffs. The same subjects should bid more in the lottery contest in order to avoid a circumstance where they do not win a prize and thus receive the lowest payoff (Herrmann and Orzen, 2008). The key reason why social preferences work in the opposite direction in the VCM and the contest is that in the VCM, individual contributions exert a positive externality on others, while in the contest individual bids exert a negative externality on others.

Another common argument for over-contribution in the VCM and over-bidding in contests is bounded rationality. Individuals often make mistakes when contributing to public goods or bidding in contests. Anderson et al. (1998) directly test this hypothesis by applying a quantal response equilibrium (QRE) model, which accounts for errors made by individual

\footnotetext{
${ }^{21}$ Several other social preference models exist which can, individually or in ensemble, explain our findings. Similar to the inequality aversion model, one can make an argument that kindness or "warm glow" can explain the negative correlation between contributions in the VCM and bids in contests. Andreoni (1995) hypothesized that one of the reasons why people contribute to public goods is kindness. Although no formal arguments have been made of what is the effect of kindness on individual behavior in contests, it is intuitive that more kind individuals should bid less in order to allow others to win the contest. Therefore, the presence of kindness would imply negative correlation between bids and contributions. Spiteful preferences are also a possible explanation for the correlation, and several studies have noted that spite plays a major role in sanctioning in public goods experiments (Falk et al., 2005). Under this model, subjects prefer to earn more than others, and therefore may over-bid in the contest but contribute less in the VCM.
} 
subjects, to the VCM. They find that depending on the magnitude of the decision error, mean contributions to the public good lie between the Nash prediction and half the endowment, and higher decision errors correspond to higher contributions. In our experiment, this implies that contributions in the VCM should be between $c^{*}=0$ and $c=40$. Sheremeta (2010a) shows how the QRE can explain some over-dissipation in lottery contests. The prediction of the QRE is that when the endowment is equal to the prize value (as it is in our experiment) then mean bids in the contest lie between the Nash prediction and half the endowment, and higher decision errors correspond to higher bids. In our experiment, this implies that bids in the contest should be between $b^{*}=15$ and $b=40$. Moreover, bounded rationality implies that subjects who make more mistakes both contribute and bid more, which should result in a positive, rather than negative, correlation between bids and contributions.

Note that the negative correlation between individual contributions and bids disappears over time. When analyzing the last five periods of the experiment, we do not find a significant correlation (correlation $0.13, p$-value $=0.43$ ). This result is not surprising, given the fact that by the end of the experiment, subjects' decisions have already been heavily influenced by the decisions of others and therefore social preferences play a less significant role in the later periods. $^{22}$

\section{Conclusion}

We investigated simultaneous decision-making in two contrasting environments: a competitive environment (lottery contest) and a cooperative environment (voluntary contribution

\footnotetext{
${ }^{22}$ We have re-estimated Table 3.2 separately for periods 1-5 and 16-20. The estimation results confirm that individual choices are significantly influenced by group choices in first five periods (p-values are less than 0.01 for the contest and VCM). On the other hand, group choices do not affect significantly individual choices in the last period (p-values are 0.71 and 0.23 for the contest and VCM).
} 
mechanism). We found that the cooperative nature of the voluntary contribution mechanism favorably influenced the contest in the simultaneous decision-making treatment by decreasing over-dissipation in the contest. This result can be explained by behavioral spillover and social interaction effects. We also found that there is a significant negative correlation between decisions made in the lottery contest and in the VCM, which can be justified by heterogeneous social preferences towards inequality but not by bounded rationality theory.

Our findings have several practical implications. It is well documented that overdissipation in contests occurs in the advertising industry as firms compete with each other in ad campaigns (Cason and Datta, 2006) and in political contests, where candidates spend more than the efficient amount on campaigning (Sheremeta, 2010b). A number of studies have tried to find ways to reduce over-dissipation, such as repetition (Davis and Reilly, 1998), constraining endowments (Parco et al., 2005; Sheremeta, 2010a), and group decision-making (Sheremeta and Zhang, 2010). Our study points out that another way to reduce over-dissipation in a contest is to allow subjects to participate simultaneously in a public goods game. In practice, this suggests that individuals participating in giving to charities or volunteering at community organizations should over-dissipate less in contests. Therefore, this may explain why the observed levels of over-dissipation in the lab are higher than in the field (Hazlett and Michaels, 1993; Sheremeta and Zhang, 2010).

Another implication of our findings is for designing optimal organizational structure of firms. It is well known that rent-seeking occurs in firms because workers, management and owners have incentives to invest resources in disputes over the firm’s profits, which reduces firm efficiency (Congleton, 2008). Firms with an organizational structure that reduces these socially wasteful activities will be relatively more efficient. For example, related work has suggested that 
certain changes to ownership structure (Muller and Warneryd, 2001; Congleton, 1989) will reduce rent-seeking. Our findings provide guidance for reducing inefficient rent-seeking activities within firms through the incorporation of more cooperative activities among workers. In particular, an organization that encourages cooperative activities within groups or promotions based on group effort may see a reduction in rent-seeking. This partly explains why greater emphasis has been placed on team work in organizations in past years, and why team work can lead to greater organizational success (Cohen, 1997).

Although game independence is a standard assumption in game theory, our findings provide clear evidence that the institutional context in which a decision is made matters for the games under study. Given that many activities in practice involve simultaneous decision-making in environments similar to contests and public goods, it is important to study these competitive and cooperative environments in ensemble. Future research should study behavioral spillovers when the contest and public goods game are played sequentially, and compare this to simultaneous behavioral spillovers. Considering other alternative environments for competition (such as first and second price auctions, oligopolistic competition, and rank-order tournaments) and cooperation (such as trust games, weakest-link public goods, and common pool resources) is also of great interest. Finally, it is important to investigate how behavioral spillovers can be used to design more efficient economic systems. We leave these extensions for future research. 


\section{References}

Anderson, S.P., Goeree, J.K., \& Holt, C.A., 1998. A Theoretical Analysis of Altruism and Decision Error in Public Goods Games. Journal of Public Economics, 70, 297-323.

Andreoni, J., 1995. Cooperation in public goods experiments: kindness or confusion. American Economic Review, 85, 891-904.

Bednar, J., \& Page, S., 2007. Can Game(s) Theory Explain Culture?: The Emergence of Cultural Behavior in Multiple Games. Rationality and Society, 19, 65-97.

Bednar, J., Chen, Y., Liu, X., \& Page, S., 2009. Behavioral Spillovers with Interdependent Institutions: An Experimental Study. University of Michigan, Working Paper.

Bernasconi, M., Corazzini, L., Kube, S., \& Marechal, M., 2009. Two are better than one! Individuals' contributions to “unpacked” public goods. Economic Letters, 104, 31-33.

Biele, G., Rieskamp, J., Czienskowski, U., 2008. Explaining cooperation in groups: Testing models of reciprocity and learning. Organizational Behavior and Human Decision Processes, 106, 89-105.

Bliss, C., \& Nalebuff, B., 1984. Dragon-slaying and ballroom dancing: The private supply of a public good. Journal of Public Economics, 25, 1-12.

Brandenburger, A.M., \& Nalebuff, B.J., 1996. Co-opetition. New York, NY: Doubleday

Camerer, C.F., 2003. Behavioral Game Theory: Experiments on Strategic Interaction. Princeton: Princeton University Press.

Cason, T., \& Datta, S., 2006. An experimental study of price dispersion in an optimal search model with advertising. International Journal of Industrial Organization, 24, 639-665.

Cason, T., Savikhin, A. \& Sheremeta, R., 2009. Cooperation Spillovers in Coordination Games. Purdue University, Working Paper.

Cherry , T.L., \& Shogren, J.F., 2007. Rationality crossovers. Journal of Economic Psychology, 28(2), 261-277.

Cherry, T.L., Crocker, T.D., \& Shogren, J.F., 2003. Rationality spillovers. Journal of Environmental Economics and Management, 45(1), 63-84.

Cohen, S.G., \& Bailey, D.E., 1997. What makes teams work: Group effectiveness research from the shop floor to the executive suite. Journal of Management, 23(3), 239-290.

Congleton, R.D., 1989. Monitoring rent-seeking managers: Advantages of diffuse ownership. Canadian Journal of Economics, 22, 662-72.

Congleton, R.D., Hilman, A.L. \& Konrad, K., 2008. Forty years of research on rent seeking: An overview. The Theory of Rent Seeking: Forty Years of Research: 1.

Croson, R., Fatas, E., \& Neugebauer, T., 2005. Reciprocity, Matching and Conditional Cooperation in Two Public Goods Games. Economics Letters, 87, 95-101.

Davis, D., \& Reilly, R., 1998. Do many cooks always spoil the stew? An experimental analysis of rent seeking and the role of a strategic buyer. Public Choice, 95, 89-115.

Dickinson, D.L. \& Oxoby, R.J., 2009. Cognitive dissonance, pessimism, and behavioral spillover effects. Working Paper.

Falk, A., Fehr, E., \& Fischbacher, U., 2005. Driving forces behind informal sanctions. Econometrica, 2017-2030.

Falk, A., Fischbacher, U., Gachter, S., \& Effects, S.I., 2009. Living in two neighborhoods social interaction effects in the lab. Working Paper.

Fehr, E., \& Gaechter, S. (2000). Cooperation and Punishment in Public Goods Experiments. American Economic Review, 90, 980-994. 
Fehr, E., \& Gaechter, S., 2000. Cooperation and Punishment in Public Goods Experiments. American Economic Review, 90, 980-994.

Fehr, E., \& Schmidt, K., 1999. A theory of fairness, competition, and cooperation. Quarterly Journal of Economics, 114, 817-868.

Fellner, G., Lunser, G., 2008. Cooperation in Local and Global Groups. Vienna University of Economics, Working Paper No. 122.

Fischbacher, U., Gächter, S., \& Fehr, E. 2001. Are people conditionally cooperative? Evidence from a public goods experiment. Economics Letters, 71, 397-404.

Fischbacher, U., Gachter, S., \& Fehr, E., 2001. Are people conditionally cooperative? Evidence from a public goods experiment. Economics Letters, 71, 397-404.

Gächter, S. 2007. Conditional cooperation. Behavioral regularities from the lab and the field and their policy implications. In B. S. Frey \& A. Stutzer (Eds.), Economics and psychology. A promising new cross-disciplinary field. Cambridge: MIT Press.

Gigerenzer, G. and Goldstein, D.G., 1996. Reasoning the Fast and Frugal Way: Models of Bounded Rationality. Psychological Review, 650-669.

Gilovich, T., Griffin, D.W., \& Kahneman, D., 2002. Heuristics and Biases: The Psychology of Intuitive Judgment. New York: Cambridge University Press.

Groves, T., \& Ledyard, J., 1977. Optimal Allocation of Public Goods: A solution to the Free Rider Problem. Econometrica, 45, 783-809.

Grund, C., \& Sliwka, D., 2005. Envy and Compassion in Tournaments. Journal of Economics and Management Strategy, 14, 187-207.

Gunthorsdottir, A., \& Rapoport, A., 2006. Embedding Social Dilemmas in Intergroup Competition Reduces Free-Riding. Organizational Behavior and Human Decision Processes, 101, 184-199.

Harrison, G. W., \& List, J. A. (2004). Field experiments. Journal of Economic Literature, 42(4), 1009-1055.

Hazlett, T. W. and Michaels, R. J., 1993. The Cost of Rent-Seeking: Evidence from Cellular Telephone License Lotteries, Southern Economic Journal, 59, 425-35.

Herrmann, B., \& Orzen, H., 2008. The appearance of homo rivalis: social preferences and the nature of rent seeking. University of Nottingham, Working Paper.

Herrmann, B., \& Thoni, C. (2009). Measuring conditional cooperation: a replication study in Russia. Experimental Economics, 12(1), 87-92.

Houser, D., \& Kurzban, R., 2002. Revisiting kindness and confusion in public goods experiments. American Economic Review, 92, 1062- 1069.

Huck, S., Jehiel, P., \& Rutter, T. (2007). Learning Spillover and Analogy-Based Expectations: A Multi-Game Experiment. UCLA, Working Paper.

Keser, C., van Winden, F., 2000. Conditional cooperation and voluntary contributions to public goods. Scandinavian Journal of Economics, 102(1), 23-39.

Kocher, M. G., Cherry, T., Kroll, S., Netzer, R. J., \& Sutter, M. (2008). Conditional cooperation on three continents. Economics Letters, 101(3), 175-178.

Ledyard, J., 1995. Public Goods: A Survey of Experimental Research. In J. Kagel and A.E. Roth (Eds.) Handbook of Experimental Economics, Princeton, NJ.

Muller, H.M. \& Warneryd, K., 2001. Inside versus outside ownership: A political theory of the firm. Rand Jounral of Economics, 32, 527-41.

Paas, F., \& Van Merriënboer, J.J.G., 1994. Instructional control of cognitive load in the training of complex cognitive tasks. Educational Psychology Review, 6, 351-371. 
Paas, F., Tuovinen, J.E., Tabbers, H., \& Van Gerven, P.W., 2003. Cognitive load measurement as a means to advance cognitive load theory. Educational Psychologist, 38, 63-71.

Potters, J.C., De Vries, C.G., \& Van Linden, F., 1998. An experimental examination of rational rent seeking. European Journal of Political Economy, 14, 783-800.

Read, D., Antonides, G., Van den Ouden, L., \& Trienekens, H., 2001. Which is Better: Simultaneous or Sequential Choice? Organizational Behavior and Human Decision Processes, 84, 54-70.

Samuelson, L., 2001. Analogies, adaptation, and anomalies. Journal of Economic Theory, 97, 320-366.

Sheremeta, R.M., \& Zhang, J., 2010. Can Groups Solve the Problem of Over-Bidding in Contests? Social Choice and Welfare, forthcoming.

Sheremeta, R.M., 2010a. Contest Design: An Experimental Investigation. Economic Inquiry, forthcoming.

Sheremeta, R.M., 2010b. Expenditures and Information Disclosure in Two-Stage Political Contests. Journal of Conflict Resolution, forthcoming.

Sheremeta, R.M., 2010c. Experimental Comparison of Multi-Stage and One-Stage Contests. Games and Economic Behavior, 68, 731-747.

Simon, H. A., 1982. Models of bounded rationality: MIT Press.

Sobel, J., 2005. Interdependent Preferences and Reciprocity. Journal of Economic Literature, 43, 392-436.

Tullock, G., 1980. Efficient Rent Seeking. In James M. Buchanan, Robert D. Tollison, Gordon Tullock, (Eds.), Toward a theory of the rent-seeking society. College Station, TX: Texas A\&M University Press, pp. 97-112.

Van Huyck, J. B., Battalio, R.C., \& Beil, R.O., 1990. Tacit coordination games, strategic uncertainty, and coordination failure. American Economic Review, 80(1), 234-48.

Weber, R., 2006. Managing growth to achieve efficient coordination in large groups. American Economic Review, 96, 114-126.

Wright, W. F., 1980. Cognitive information processing biases: Implications for producers and users of financial information. Decision Sciences, 11, 284-298. 


\section{Appendix - Instructions (Contest-VCM Treatment)}

INSTRUCTIONS: In this experiment you will participate in a game with three other participants. You will not know the identity of the participants you are grouped with. The experiment will consist of $\mathbf{2 0}$ periods. You will participate in both a BLUE GAME and a GREEN GAME at the same time and with the same participants. The BLUE GAME will appear on the left side of the screen and the GREEN GAME will appear on the right side of the screen at the same time in all 20 periods.

At the end of the experiment $\mathbf{2}$ out of $\mathbf{2 0}$ periods will be randomly selected for payment for the BLUE GAME and 2 out of 20 periods will be randomly selected for payment for the GREEN GAME. After you have completed all periods two tokens will be randomly drawn out of a bingo cage containing tokens numbered from 1 to 20. The token numbers determine which two periods are going to be paid in the BLUE GAME. These tokens will be returned to the bingo cage, and two tokens will be randomly drawn again out of a bingo cage containing tokens numbered from 1 to 20. The token numbers determine which two periods are going to be paid in the GREEN GAME.

Each period you will be given $\mathbf{8 0}$ francs for the BLUE GAME and $\mathbf{8 0}$ francs for the GREEN GAME. Francs will be converted to U.S. dollars at the end of the experiment at the rate of $\mathbf{2 5}$ francs $=\mathbf{\$ 1}$. Each period, you will select a bid for the BLUE GAME and an allocation for the GREEN GAME. When you are ready to make your decision, click on the "input boxes" below "How much would you like to bid?" and "How much would you like to allocate to the Group Account?" and the program will allow you to enter in your number choices. When you are finished making your choices, click "Submit".

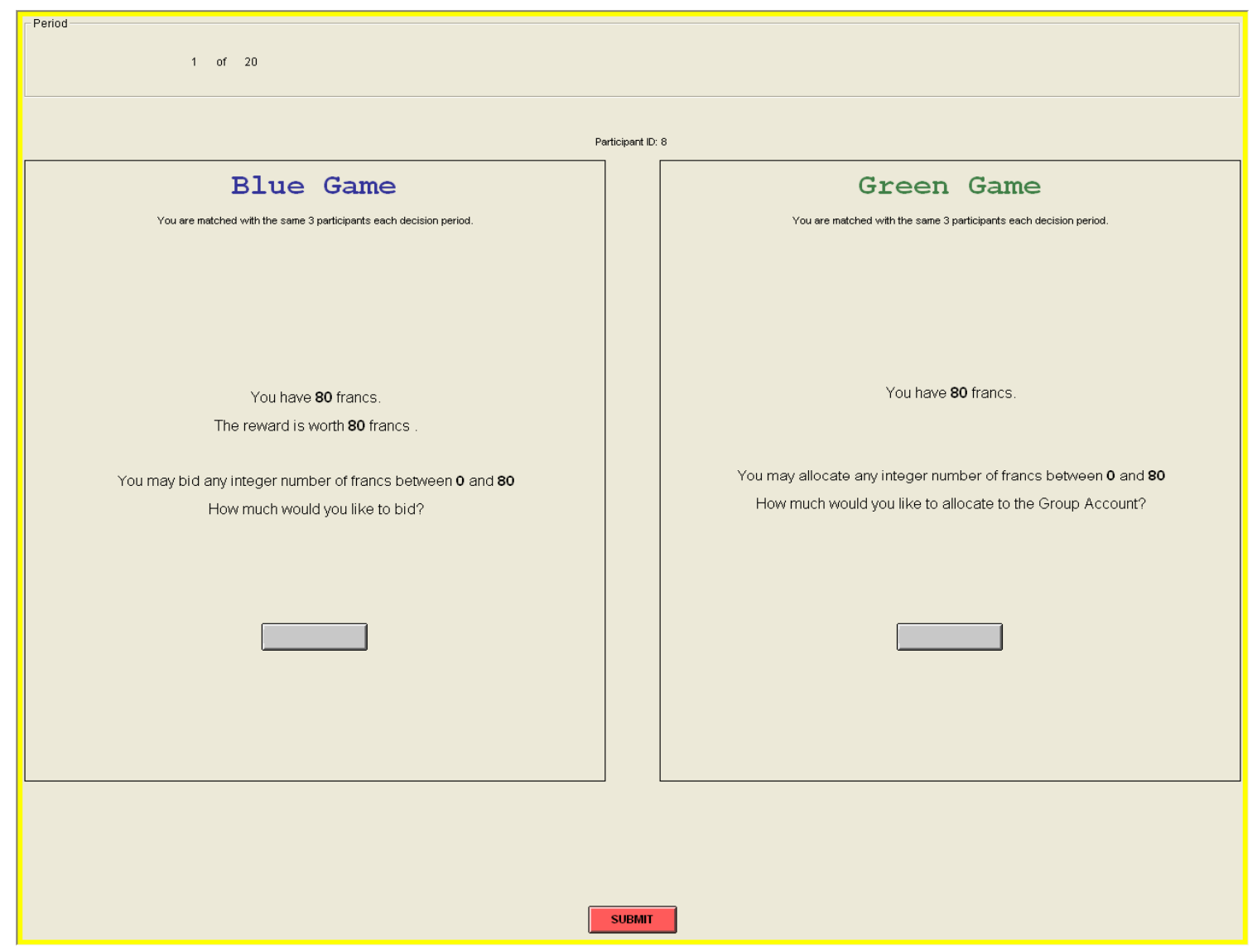

BLUE GAME: Each period, you and all other participants will be given an initial endowment of $\mathbf{8 0}$ francs and you will be asked to decide how much you want to bid for a reward. The reward is worth $\mathbf{8 0}$ francs to you and the other three participants in your group. You may bid any integer number of francs between $\mathbf{0}$ and $\mathbf{8 0}$. After all participants have made their decisions, your earnings for the period are calculated. These earnings will be converted to cash and paid at the end of the experiment if the current period is the period that is randomly chosen for payment. If you 
receive the reward your period earnings are equal to your endowment plus the reward minus your bid. If you do not receive the reward your period earnings are equal to your endowment minus your bid.

If you receive the reward: $\quad$ Earnings $=$ Endowment + Reward - Your Bid $=80+80-$ Your Bid

If you do not receive the reward: Earnings $=$ Endowment - Your Bid $=80-$ Your Bid

The more you bid, the more likely you are to receive the reward. The more the other participants in your group bid, the less likely you are to receive the reward. Specifically, for each franc you bid you will receive one lottery ticket. At the end of each period the computer draws randomly one ticket among all the tickets purchased by $\mathbf{4}$ participants in the group, including you. The owner of the drawn ticket receives the reward of 80 francs. Thus, your chance of receiving the reward is given by the number of francs you bid divided by the total number of francs all 4 participants in your group bid. You can never guarantee yourself the reward. However, by increasing your bid, you can increase your chance of receiving the reward. Regardless of who receives the reward, all participants will have to pay their bids.

Chance of receiving the

reward

$=\frac{\text { Your Bid }}{\text { Sum of all } 4 \text { Bids in your group }}$

In case all participants bid zero, the reward is randomly assigned to one of the four participants in the group.

Example: This is a hypothetical example used to illustrate how the computer is making a random draw. Let's say participant 1 bids 10 francs, participant 2 bids 15 francs, participant 3 bids 0 francs, and participant 4 bids 40 francs. Therefore, the computer assigns 10 lottery tickets to participant 1,15 lottery tickets to participant 2, 0 lottery tickets to participant 3 , and 40 lottery tickets for participant 4 . Then the computer randomly draws one lottery ticket out of $\mathbf{6 5}(10+15+0+40)$. As you can see, participant 4 has the highest chance of receiving the reward: $\mathbf{0 . 6 2}=\mathbf{4 0 / 6 5}$. Participant 2 has $0.23=\mathbf{1 5} / \mathbf{6 5}$ chance, participant 1 has $\mathbf{0 . 1 5}=\mathbf{1 0} / \mathbf{6 5}$ chance, and participant 3 has $\mathbf{0}=\mathbf{0} / \mathbf{6 5}$ chance of receiving the reward.

After all participants make their bids, the computer will make a random draw which will decide who receives the reward. Then the computer will calculate your period earnings based on your bid and whether you received the reward or not.

GREEN GAME: Each period you will be given $\mathbf{8 0}$ francs and you will be asked to decide how much of this amount you want to allocate to a Group Account. The remainder will be automatically allocated to your Individual Account. You may allocate any integer number of francs between $\mathbf{0}$ and $\mathbf{8 0}$. After all participants have made their decisions, your earnings for the period are calculated. These earnings will be converted to cash and paid at the end of the experiment if the current period is the period that is randomly chosen for payment. Your earnings consist of two parts

1) Your earnings from the Individual Account

2) Your earnings from the Group Account

Your earnings from the Individual Account equal to the francs that you keep for yourself and do not depend on the decisions of others. Therefore, for every franc you keep for yourself in your Individual Account, you earn $\mathbf{1}$ franc.

Your earnings from the Group Account depend on the total number of francs allocated to the Group Account by all 4 group members (including you). In particular, your earnings from the Group Account are $\mathbf{4 0}$ percent of the total allocation of all 4 group members (including you) to the Group Account. Therefore, for every franc you allocate to the Group Account, you increase the total allocation to the Group Account by 1 franc. Therefore, your earnings from the Group Account rise by $0.4 \times 1=0.4$ francs. And the earnings of the other group members also rise by 0.4 francs each, so that the total earnings of the group from the Group Account rise by 1.6 francs.

In summary, your period earnings are determined as follows:

Your earnings $=$ earnings from the Individual Account + earnings from the Group Account $=$ $=80-$ (your allocation to the Group Account) $+0.4 \times$ (allocation of 4 group members to the Group Account) 
Example: Suppose that you allocated 40 francs to the Group Account and that the other three members of your group allocated a total of 120 francs. This makes a total of 160 francs in the Group Account. In this case each member of the group receives earnings from the Group Account of $0.4 \times 160=64$ francs. In addition, you also receive 40 francs from your Individual Account since you have kept 40 francs to your Individual Account.

\section{OUTCOME SCREEN}

BLUE GAME: At the end of each period, your bid, the sum of all bids in your group, whether you received the reward or not, and the earnings for the period are reported on the outcome screen as shown below. Once the outcome screen is displayed you should record your results for the period on your Personal Record Sheet under the appropriate heading.

GREEN GAME: At the end of each period, your allocation and the sum of all allocations in your group are reported on the outcome screen as shown below. To aid you in your calculation, you are also shown your income from your individual account and your income from the group account. Once the outcome screen is displayed you should record your results for the period on your Personal Record Sheet under the appropriate heading.

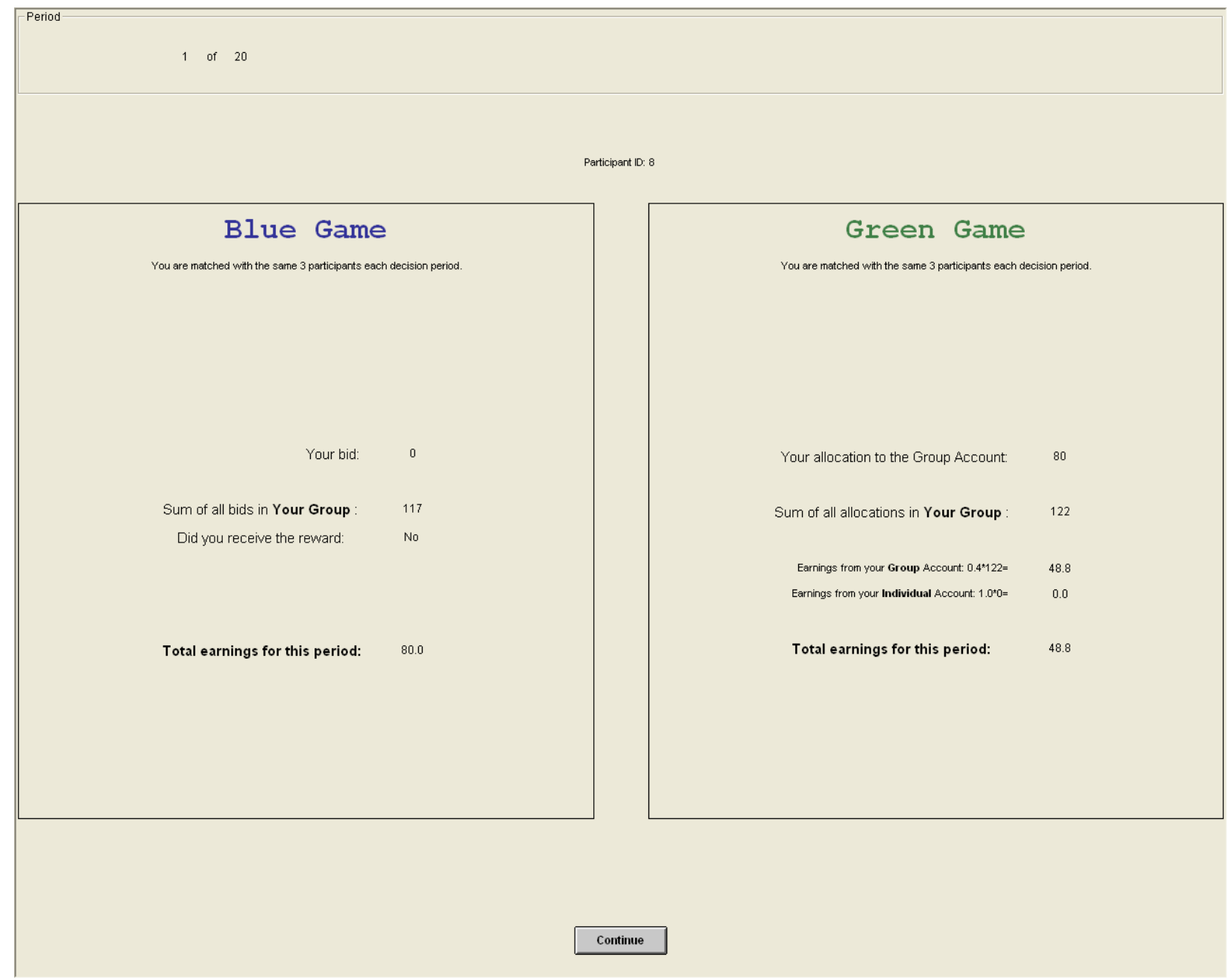




\section{Economic Science Institute Working Papers}

2010

10-07 Chowdhury, S. and Sheremeta, R. A generalized Tullock contest.

10-06 Chowdhury, S. and Sheremeta, R. The Equivalence of Contests.

10-05 Shields, T. Do Analysts Tell the Truth? Do Shareholders Listen? An Experimental Study of Analysts' Forecasts and Shareholder Reaction.

10-04 Lin, S. and Rassenti, S. Are Under- and Over-reaction the Same Matter? A Price Inertia based Account.

10-03 Lin, S. Gradual Information Diffusion and Asset Price Momentum.

10-02 Gjerstad, S. and Smith, V. Household expenditure cycles and economic cycles, 1920 - 2010.

10-01 Dickhaut, J., Lin, S., Porter, D. and Smith, V. Durability, Re-trading and Market Performance. 2009

09-11 Hazlett, T., Porter, D., Smith, V. Radio Spectrum and the Disruptive Clarity OF Ronald Coase.

09-10 Sheremeta, R. Expenditures and Information Disclosure in Two-Stage Political Contests.

09-09 Sheremeta, R. and Zhang, J. Can Groups Solve the Problem of Over-Bidding in Contests?

09-08 Sheremeta, R. and Zhang, J. Multi-Level Trust Game with "Insider" Communication.

09-07 Price, C. and Sheremeta, R. Endowment Effects in Contests.

09-06 Cason, T., Savikhin, A. and Sheremeta, R. Cooperation Spillovers in Coordination Games.

09-05 Sheremeta, R. Contest Design: An Experimental Investigation.

09-04 Sheremeta, R. Experimental Comparison of Multi-Stage and One-Stage Contests.

09-03 Smith, A., Skarbek, D., and Wilson, B. Anarchy, Groups, and Conflict: An Experiment on the Emergence of Protective Associations.

09-02 Jaworski, T. and Wilson, B. Go West Young Man: Self-selection and Endogenous Property Rights.

09-01 Gjerstad, S. Housing Market Price Tier Movements in an Expansion and Collapse.

2008

08-10 Dickhaut, J., Houser, D., Aimone, J., Tila, D. and Johnson, C. High Stakes Behavior with Low Payoffs: Inducing Preferences with Holt-Laury Gambles. 
08-09 Stecher, J., Shields, T. and Dickhaut, J. Generating Ambiguity in the Laboratory.

08-08 Stecher, J., Lunawat, R., Pronin, K. and Dickhaut, J. Decision Making and Trade without Probabilities.

08-07 Dickhaut, J., Lungu, O., Smith, V., Xin, B. and Rustichini, A. A Neuronal Mechanism of Choice.

08-06 Anctil, R., Dickhaut, J., Johnson, K., and Kanodia, C. Does Information Transparency

Decrease Coordination Failure?

08-05 Tila, D. and Porter, D. Group Prediction in Information Markets With and Without Trading Information and Price Manipulation Incentives.

08-04 Caginalp, G., Hao, L., Porter, D. and Smith, V. Asset Market Reactions to News: An Experimental Study.

08-03 Thomas, C. and Wilson, B. Horizontal Product Differentiation in Auctions and Multilateral Negotiations.

08-02 Oprea, R., Wilson, B. and Zillante, A. War of Attrition: Evidence from a Laboratory Experiment on Market Exit.

08-01 Oprea, R., Porter, D., Hibbert, C., Hanson, R. and Tila, D. Can Manipulators Mislead Prediction Market Observers? 